JELTL (Journal of English Language Teaching and Linguistics) e-ISSN: 2502-6062, p-ISSN: 2503-1848

2018, Vol. 3 (1)

www.jeltl.org

\title{
Group Dynamics and Student Participation in a Chinese Setting: Teacher and Observer Perspectives
}

\author{
John Harper \\ Shantou University, China \\ e-mail:johnh@stu.edu.cn \\ Hui-ju Chen \\ Shantou University, China \\ e-mail:mickeyc@stu.edu.cn
}

\begin{abstract}
This article addresses the frequently discussed notion of Chinese students' supposed reticence and passivity in the English as a Foreign Language classroom. Using the concept of group dynamics as a starting point, it examines teachers' classroommanagement techniques in terms of promoting (or not promoting) active student participation. The study, using a grounded theory of research, analyzed classroom data obtained from class observations and from class filmings and supplemented these data with post-lesson interviews with the four involved teachers. Findings suggested that Chinese students were not necessarily reticent or passive but rather engaged actively when given a learning environment conducive to active engagement. The study pointed to three practical implications for classroom teachers: (1) promoting participation by working toward group cohesion, (2) promoting participation by providing effective teacher-student scaffolding and by providing opportunities for student-student scaffolding, (3) promoting participation by actively replacing textbook materials in order more effectively to offer students adequate support in terms of both language and affect. Acknowledging the fact that different institutional contexts may require different classroom-management techniques, the study calls for further testing of the present findings in other Chinese settings.
\end{abstract}

Keywords: affective factors, group dynamics, motivation, reticence, scaffolding 


\section{INTRODUCTION}

ESL/EFL literature abounds with discussions of Chinese students' lack of participation in English classes. Some commentators (e.g., Cortazzi \& Jin, 1996; Flowerdrew \& Miller, 1995) attribute Chinese students' supposed unwillingness to participate to cultural factors. Among these factors, it is argued, are Chinese students' respect for the teacher's authority and interest in maintaining a collectivist harmony in the classroom. Others (e.g., Li \& Baldauf, 2011; Lin \& Wu, 2012; Zhu, 2003) point to aspects of the teaching-learning situation that are largely out of the learners' control. When faced with an exam-oriented curriculum or an overcrowded classroom, students may have few chances to participate actively in class. Still others (e.g., Liu \& Jackson, 2008; Tsui, 1996) explain the phenomenon through a consideration of affective factors such as communication apprehension and fear of negative evaluation.

Undoubtedly, some Chinese students, like some students of any other cultural background, may show signs of reticence in the classroom. As pointed out above, various explanations may be given for this reticence. While an analysis of the causes of lack of participation is certainly necessary, a search for solutions would also seem desirable. Hence, this paper, after examining causes in some detail, will report on a classroom-based study carried out at the English Language Center (ELC) of Shantou University (Guangdong Province, China). The study examines the relation between teachers' group-management techniques and student participation. It is based on the assumption that the classroom teacher, as a key participant in the "classroom drama" (Nunan, 1996, p. 53), has a particular insight into the culture of his/her particular class (see also Freeman, 1996, 2002; Kumaravadivelu, 2001). For this reason, the insights of both the observers (i.e., the authors of this paper) and the observed teachers will be taken into account.

\section{LITERATURE REVIEW}

\subsection{Possible Causes of Chinese Students' Lack of Participation}

Cortazzi and Jin (1996) argue that students' classroom behavior can be explained through an analysis of their "culture of learning." They suggest that Chinese students want a "structured learning programme [that is] at variance with communicative approaches" (p. 170; see also Zhu, 2003). This "culture of learning," according to Cortazzi and Jin, is one that promotes learning through rote memory and imitation, not through creativity or spontaneity. Such a culture of learning is said to lead to a situation in which students rarely initiate conversation or ask questions. The asking of questions would cause a student to stand out among his/her peerssomething that is discouraged in a collectivist culture such as that of China. Furthermore, the student who asks questions runs the risk of losing face if his/her questions are deemed "foolish" (p. 194). And the asking of questions is also said to present a challenge to the teacher, who is expected to predict students' questions and answer them before they are asked.

Flowerdrew and Miller (1995) also attribute Chinese students' supposed reticence to cultural factors, particularly to those related to Confucian ideas (see also Zhu, 2003). In discussing a study carried out at City University of Hong Kong, the 
authors point out that "Chinese students adopt a receptive role in class and look to the teacher to provide the information needed to successfully pass the course" (pp. 348-349). Reasons given for such a passive stance toward education echo those given by Cortazzi and Jin (1996): respect for authority, fear of losing face, desire to maintain harmony in a collectivist culture. Flowerdrew and Miller report that Chinese students inadvertently create a great deal of frustration for Western teachers who attempt to implement an "interactive style of lecturing" (p. 357).

The cultural interpretation of Chinese students' supposed lack of participation is not without its critics. Cheng (2000), arguing that Chinese students are "not culturally predisposed to be reticent and passive in language learning" (p. 438), refutes the notion that Chinese students' reticence, when it exists, should be attributed to Confucian ideas:

$[R]$ especting knowledge and knowledgeable teachers does not mean students should be compliant and passive to the teacher. This is manifested in Confucius's well-known saying: "shi bu bi xian yu di zi; di zi bu bi bu ru shi", which means "the teacher does not always have to be more knowledgeable than the pupil; and the pupil is not necessarily always less learned than the teacher". Confucius had another saying which is known to virtually every household in China "san ren xing, bi you wo shi", meaning "among any three persons, there must be one who can be my teacher". Obviously Confucius was not in favour of the idea that the pupils should blindly accept whatever the teacher imparts (p. 440; see also Liu \& Littlewood, 1997; Kumaravadivelu, 2003).

If the Chinese culture of learning cannot necessarily be considered the primary contributing cause of Chinese students' passivity, the question arises as to what the causes might be. Cheng (2000) focuses on two possibilities: (1) inappropriate methodologies on the part of the teacher and (2) lack of English proficiency on the part of the students. He makes the point that students in a teacher-centered classroom "are doomed to reticence and passivity" (p. 442; see also Xie, 2010). He then points out that Western teachers of English often "impose" communicative methodologies on students without considering whether or not the students are ready for them (p. 444; see also Xie, 2014).

The issue of inappropriate methodologies - or inappropriately implemented methodologies--indicates that a lack of participation is sometimes out of the students' control. Although the possibility of having students participate in decisions concerning course content is sometimes mentioned (e.g., Dörnyei, 1994; Hedge, 2000; Nunan, 1995), it is safe to say that teaching methodologies are normally left to curriculum designers, program administrators, and classroom teachers, with students having a limited role in the decision-making process. Inappropriate methodologies, incidentally, are not the only constraints that may lessen Chinese learners' participation in English lessons. As mentioned above, overcrowded classrooms and exam-oriented curriculums are sometimes cited as hindrances to effective communicative teaching in Chinese settings. Additionally, commentators analyzing 
the difficulties of implementing communicative approaches in China have pointed to a lack of stimulating materials and a lack of adequate in-service training in these approaches (see Li \& Baldauf, 2011; Lin \& Wu, 2012). Clearly, then, when passivity is noticed in Chinese students, one must consider a plethora of possible causes, some of which may be attributed to factors external to the students themselves (see $\mathrm{Hu}, 2005$ ).

The second possibility that Cheng (2000) mentions-i.e., lack of English proficiency - may be connected to affective factors as well. Cheng notes that a prior focus on receptive skills may leave students unprepared to participate in discussions with native speakers of English. One may suppose that a lack of English proficiency, or a perceived lack of proficiency, is likely to increase Chinese students' Englishspeaking anxiety even in a predominantly Chinese setting. Liu and Jackson (2008), in reporting on a study carried out with 547 first-year undergraduates at Tsinghua University, note that "more than one third of the participants felt anxious in their English language classrooms" (p. 82). Tsui (1996) sought the opinions of 38 teachers in Hong Kong and found that "low English proficiency" and "fear of making mistakes and being ridiculed by classmates" were two of the five causes of students' unwillingness to participate (p. 155). And Liu and Littlewood (1997), in carrying out two large-scale surveys at the University of Hong Kong, identified "lack of experience in speaking English," "lack of confidence in spoken English," and "anxiety from high performance expectations" as principal causes of student reticence (pp. 375-376).

As the preceding comments should reveal, there is no definitive explanation as to why some Chinese students may seem passive and reticent in class. Also, it seems clear that some of the explanations may be associated with any group of language learners, not just with Chinese learners. Language-learning anxiety, for example, can hardly be considered a culture-specific phenomenon (see Kumaravadivelu, 2003). Nevertheless, some Chinese students "are indeed reticent and passive" (Cheng, 2000 , p. 438). As mentioned previously, this paper will seek to show how groupmanagement techniques may affect student participation in a Chinese setting. Prior to a discussion of the study itself, some mention of group dynamics is in order.

\subsection{Group Dynamics and Student Participation}

The study of group dynamics rests essentially on the commonsense notion that the group brings with it more resources than does any individual member of the group (Dörnyei \& Malderez, 1997; Oxford, 1997). As Dörnyei and Malderez (1997) point out, a group has a "life of its own" (p. 68; see also Prabhu, 1987). Hence, when working in a group, students may behave differently than they would in another setting (Dörnyei \& Malderez, 1997). The cohesion of the group greatly influences students' willingness to participate in classroom tasks. As a case in point, Clément, Dörnyei, and Noels (1994), in their study of 301 students in a monolingual setting in Budapest, found that a "good classroom atmosphere" served as an important factor in increasing motivation, decreasing anxiety, and therefore promoting student interaction (p. 442). 
As a fundamental element in creating group cohesion, positive group dynamics may also create a platform for peer scaffolding, "the dialogic process by which one speaker assists another in performing a function that he or she cannot perform alone" (Ellis, 2003, pp. 180-181). The most basic definition of scaffolding holds that a more capable person (i.e., a teacher or a more qualified student) should create the circumstances in which a somewhat less capable individual may appropriate the skills necessary for further development (Block, 2003; see also Nunan, 2004; Prahbu, 1987). Sociocultural theory, however, has consistently revealed that scaffolding does not necessarily have to take a top-down format. Lantolf and Thorne (2006), citing Donato (2004), mention that students working in groups may form a sort of "collective expert" and may thus carry out tasks that could not be done by any one individual (p. 283; see also Antón, 1999; Ellis, 2003; Wells, 1999). As Naughton (2006) puts it, "Learners are seen to be mutual scaffolders who give and receive support as they interact with their peers" (p. 170; see also Oxford, 1997).

Due to its ability to create an appropriate environment, and due to its ability to create the conditions in which students can be "mutual scaffolders," the group must be considered a primary factor in successful language learning in a classroom setting. Where, then, does the teacher come into play? It is well known that, in the current communicative and task-based methodologies, the teacher serves as more of a facilitator and less of an all-knowing font of knowledge (see, for example, Bejarano, 1987). One aspect of the role of facilitator is that of representing the "group conscience" and therefore leading students to be willing to put forth the time and effort needed to acquire another language (Dörnyei, 1994, p. 278, italics as in original). Another aspect is that of creating a learning environment conducive to language learning (Dörnyei, 2001). And yet another is that of choosing and presenting a learning task in an efficient and effective manner so that learners know what they are doing, why they are doing it, and how they should do it (Dörnyei, 1994; see also Block, 1996; Brindley, 1984; Crabbe, 2003; Crabbe 2007; Hedge, 2000; Kumaravadivelu, 1994; Nunan, 1995). Clearly, the teacher/facilitator's manner of dealing with groups will determine to a large extent the language-learning opportunities made available to students and the degree of participation that can be expected from them.

\section{RESEARCH METHODS}

\subsection{Research Design}

The classroom-based study reported here sought to examine the way in which teachers' group-management techniques enhanced or inhibited Chinese students' classroom participation. The study took place at the English Language Center (ELC) of Shantou University during the Fall Semester of 2017. A grounded theory of research was used. No presuppositions were made concerning how teachers should or should not manage groups. Instead, teachers were observed, filmed, and consulted to see how they managed groups in order to promote active student participation. The data were transcribed and coded, and insights were gathered according to the data (see Dörnyei, 2007; Friedman, 2012). The observers' (i.e., the authors') 
thoughts concerning group management were considered an element in the study but definitely not an element superior to the observed teachers' views of their own lessons.

The research questions guiding the study were the following:

1) In what ways do teachers' group-management techniques enhance student participation?

2) In what ways do teachers' group-management techniques inhibit student participation?

3) How do teachers themselves view their management of groups in terms of promoting participation?

\subsection{Institutional Context}

Shantou University is a key provincial university in Guangdong Province, China. The ELC offers a four-semester program for almost all of the students of the school. Classes meet twice a week for 90 minutes each time. Students earn a total of 16 credit hours for their study of English - though many choose to undertake additional study through elective courses such as Voice \& Accent, Art \& Culture, Public Speaking, Translation \& Culture, etc. The principle of integrated skills is present throughout the entire program. In keeping with the College English Curriculum Requirements of 2007 set by the Chinese Ministry of Education, the ELC has established the Five Golden Rules of English Learning: proficiency, autonomy, sustainability, intercultural communication, and critical thinking.

The ELC-1 course was chosen for the study because the huge majority of students in the course were freshmen who, in all likelihood, would have come straight out of a high school curriculum focused more on the analysis of language than on the production of language (Jin, Liu, \& Zhang, 2015). In other words, most students in ELC-1 classes were exposed to a communicative curriculum for the first time when they arrived at Shantou University. The classroom teachers, then, as the "group conscience," needed to take on the task of forming a cohesive group with students from different cities/towns, of different majors, with different interests, and with different learning goals. As all classroom teachers need to "worry about about balancing skills and competencies, pace and variety, [and] keeping up with the latest descriptions of language and communication and 'translating' them into pedagogical realities" (Dörnyei \& Malderez, 1997, pp. 66-67), it is safe to say that the commitment involved in teaching a group of predominantly freshmen in ELC-1 presents a fairly tall order for the classroom teacher.

\subsection{The Cohort}

The teachers participating in the study were two Chinese and two Americans, with a range from one to five years of experience at the ELC and from two to seven years of total ESL/EFL experience. Although no attempt was made to compare Chinese teachers' methods to those of international teachers, an effort was made to elicit the help of both local and international teachers in order to obtain a representative sample (as the ELC maintains a roughly equal balance between the 
two). The four teachers-Angela, Nick, Paul, and Shawna--all signed a consent form and willingly agreed to participate in the study.

\subsection{Data Collection and Analysis}

As mentioned above, the study reported here was based on data gathered from filmed classroom observations. In each case, an entire 90-minute lesson was observed by one or the other of the authors of this paper and filmed by a student assistant. Data-gathering was planned largely around the teachers' course schedules, with efforts being made to avoid observations on days when lessons centered around in-class writing, oral presentations, or other evaluative measures that might reduce the possibility of experiencing teachers' group-management techniques. During observations, the observers took copious field notes. After the observations, the class filmings were reviewed by the authors and by the classroom teachers. The observed classes were then analyzed with the teachers in recorded interviews. During the dataanalysis process, three common themes regarding what generally "worked" in terms of group-management techniques promoting student participation were identified: (1) creating an atmosphere conducive to active student engagement, (2) making use of scaffolding techniques and providing opportunities for peer scaffolding, (3) replacing textbook materials in order to meet students' needs/interests.

\section{FINDINGS}

\subsection{Creating an Atmosphere Conducive to Active Student Engagement}

Much has been said about the connection between a tight-knit learner group and student interaction. As mentioned previously, Clément, Dörnyei, and Noels (1994) found a significant relation between group cohesion and student participation. Other commentators share the view that the learner group strongly influences the degree of student involvement. Chang (2010) notes that "a cohesive group learns more efficiently because the members feel more at ease when speaking and sharing ideas" (pp. 131-132), and Effiong (2016) suggests that learners are more likely to take risks (hence, participate) in an "enabling and cooperative classroom environment" (p. 135). Needless to say, the teacher plays an important role in establishing the conditions in which a cohesive group and the resulting opportunities for interaction may be created. Thus, Xie (2010) argues that teachers must develop "an academically motivating, caring, and safe interactive atmosphere with students" in order to be able "to facilitate and promote meaningful interaction and optimize learning opportunities" (p. 11). In the classes observed for the purposes of this study, three practices particularly stood out in terms of creating an environment conducive to student engagement: (1) starting the lesson in a dynamic fashion, (2) using a variety of work formations, (3) creating a relaxed atmosphere through the use of humor.

\subsubsection{Starting the Lesson in a Dynamic Fashion}

The mood that is created at the start of a lesson is likely to carry over to other parts of the lesson (see Nunan, 1996). All four classes analyzed here began with warmup activities. Two, however, got into the warmup activity within the first 
minute and a half of the lesson. After greeting the students and introducing the observer and the photographer, Angela immediately launched into the warmer-as the following excerpt will reveal.

Excerpt \#1: Angela: classroom: October 25, 2017

Angela: Alright. So, before we get started, I'd like you to say HELLO to Teacher Mickey [i.e., the observer], in the back.

Students [almost in chorus]: Hello.

Mickey: Hello.

Angela: So, Mickey is my colleague. She also teaches Level 1. And then can you say HELLO to... uhmmm.... [looks at photographer] What's your name?

Photographer: Jenny.

Angela: Can you say HELLO to Jenny?

Students [almost in chorus]: Hello.

Angela: And can you say HELLO to the camera?

Students [laughing, with enthusiasm, waving to the camera]: Hello.

Angela: First of all...first of all, we're going to have a warmup activity, as usual, right? You're going to stand up, circulate around the room, and ask your partners the following questions. OK? Let's have a look [shows questions on powerpoint slide]. Number 1: Do you like traveling? If yes, why do you travel...like your purposes? And then, if not, why not? Number 2: Is there anywhere you would particularly like to visit? Why? For example, you say "I would really like to go to Paris" or "I wish I had a chance to visit Tibet." Something like that. OK? Do you know what to do?

Students [nodding heads]: Yes. Yeah.

Angela: Perfect. OK, stand up!

Like Angela, Paul also moved straight into the warmup activity (even prior to mentioning lesson goals).

Excerpt \#2: Paul: classroom: October 20, 2017

We're talking about food. And...before we start, a quick warmup. With your partner...with your partner..., just talk about what this means to you [points to powerpoint slide]: "The way to a man's heart is through his stomach." So, with your partner, what does it mean? What do you think it means? And is it true? OK, so with your partner, in just two minutes...quickly... what does it mean?

By moving into the warmup activity straightaway, both Angela and Paul set the tone for an active, dynamic lesson. They also provided students with a chance to re-establish relationships within the learner group and to make the mental transition from the Chinese environment outside the classroom to the English environment inside the classroom. And as the warmup activities were accessible to all students, the teachers, by implementing these activities, started the lesson by providing students with an expectation of success, an expectation which likely served to heighten students' confidence from the outset. 
Paul's comments on the almost immediate implementation of a warmer were as follows:

Excerpt \#3: Paul: interview: October 30, 2017

I think...sometimes, even when students come to class and I start...if I start...class by just talking and stuff, students aren't really with me. I still don't feel like the students.... Students aren't really with me there.... I kind of want to start...right away...start with something, catch their interest, get them paying attention, kind of set the...set the mood....

The comments suggest that Paul is well aware that students, upon entering their English class, may not be fully focused on the class. Hence, a dynamic, short-butsweet warmup activity serves to direct their energy to the upcoming lesson.

It should be noted that, in the two classes discussed above, lively participation ensued as soon as the warmup activity started. In the other two classes, warmups occurred-but in a much less impacting manner. In Nick's class, for example, the lesson began with a roll call. Afterwards, the teacher showed a set of seven vocabulary items that the students would review. He then instructed the students to work individually to categorize the vocabulary items according to their degree of familiarity with them (i.e., I've never heard or seen this word before. / I can explain the meaning of the word and use it in a sentence). After about nine minutes, the teacher instructed the students to circulate around the room in search of classmates who could explain unfamiliar items. The activity served the purpose of encouraging a certain degree of self-reflection among students. However, it did not produce the sort of lively participation that was evidenced in the other classes discussed above. In short, while the practice of raising students' awareness of their own learning stands out as a learning opportunity in and of itself (see Crabbe, 2007), the data analyzed here suggest that, if a warmup activity is to promote active participation, it needs to take place without any significant delay.

\subsubsection{Using a Variety of Work Formations}

Numerous benefits of employing a variety of work formations have been reported in the ESL/EFL literature. The practice of regularly moving students around may help to suit the demands of a particular task, to prevent the establishment of classroom cliques, and to provide learners with the opportunity to "create intermental communications with as many other students as possible" (Dörnyei \& Murphey, 2003, p. 86; see also Chang, 2010). In the classes analyzed here, all teachers employed at least four different work formations, with Shawna employing five (i.e., whole-class work, individual work, pair work, group work, and cocktail-party-style mingling). Nick, who gave his students the task of designing a themed-based restaurant, explained his use of varied work formations rather succinctly:

Excerpt \#4: Nick: interview: November 3, 2017

Having that kind of variety...you know...just kind of breaks things up-breaks up a sense of monotony. I think it causes different kinds of interaction to happen. You know...in a pair work kind of situation, 
you're just kind of back and forth between...between two people. They're sharing ideas, opinions... or maybe asking each other questions directly about something. But then group work...they're working together with two or three or four other people...to create somethingin this case, a restaurant. So, I'm hoping that there's some kind of way that they're breaking up the work...or they're each contributing ideas that they can use for their end product.

And when Nick was asked which type of work formation he preferred, he again provided a very to-the-point answer: "I think that depends on what my end goal is."

Nick clearly sees the changing up of work formations as a means of maintaining a dynamic, communicative atmosphere in the classroom. It is apparent, however, that he also sees particular formations as being particularly suitable for the achievement of particular goals. In other words, as mentioned above, group formations may be changed according to task requirements. The point, in short, is that group arrangements are changed for a reason, not just for the sake of changing them.

Shawna takes the notion of varied work formations one step further by changing the seating arrangement each class period. In the class observed, she entered a few minutes early and placed pre-prepared name cards at strategic locations. The students, obviously familiar with the technique, entered the classroom and looked for their names. The result was that the students, well accustomed to sitting in groups, sat with classmates who had not been their groupmates in previous lessons. While acknowledging some difficulties in implementing an ongoing change of seating arrangement, Shawna explained the benefits as follows:

Excerpt \#5: Shawna: interview: October 31, 2017

At the very beginning, I think it's very hard because they don't know each other-especially, they need to talk...girls with boys. So, it's a little bit awkward the first time. But once they get to know each other, they get...they get interest to talk with different people. And I think it's better for them to improve their interpersonal skills. Normally, I will divide them into several groups - normally, I will have four people in one group, right? So, in that small group, I will set one active student....and naturally that student will be the leader of that group. And the active students will have...like... relatively silent students...the silent partner. So they will work together..... And after several weeks, I found...I think...they can be influenced by each other. I mean...the silent students...the shy students... will be more likely to talk. Maybe they think, OK, I want to get more things from my partner.

In making this comment, Shawna reveals an awareness that, if student collaboration is expected, opportunities for the development of interpersonal skills need to be provided (see, Bejarano, 1987; Oxford, 1997). The teacher, in using some of her preparation time to rework, continuously, the class seating arrangement, enables learners to develop interpersonal skills and at the same time produces a sort of "facilitative anxiety," a sense of "newness" that awaits students every class period 
and that in itself may lead to increased interaction (Dörnyei \& Murphey, 2003, p. 86).

\subsubsection{Creating a Relaxed Atmosphere through the Use of Humor}

While humor certainly cannot be considered a pre-requisite for student involvement in class, the positive effects of a humorous classroom have been extensively noted. Humor can make course materials more attractive, reduce anxiety, and serve as a healthy antidote to the face-threatening nature of classroom language learning (see Effiong, 2016; Pomerantz \& Bell, 2011; Swanson, 2013). The teachers observed in this study would appear to agree with the benefits of humor. Specifically, Nick pointed out that humor made the class "more interesting" for the students and for himself; Shawna noted that jokes helped to improve the relationship between herself and the students; and Angela mentioned that she spontaneously reacted to students' humor because she wanted to share the moment with them.

During his observed class, Paul provided an interesting example of a teacher's use of humor and later provided his thoughts concerning the benefits of humor in the classroom.

Excerpt \#6: Paul: classroom: October 20, 2017

Paul [after break, with feigned serious face]: Alright. Pleasure's over. Fun's over. So, a quick announcement before we continue the lesson. I've got...I've got something [reaches into wallet and pulls out money]. I've got some....

Students [laughing]: Ohhhhh.

Paul: Do you want some money?

Students [laughing]: Yeah! No!

Paul: Alright. I have an announcement. If you like money, and if you want money, then we have a video contest - I think I mentioned this before. And you can win 500RMB! [again picks up his own money] This is just 200. This is nothing.

Excerpt \#7: Paul: interview: October 30, 2017

I actually kind of want to have a more...not-so-top-down approach to teaching with these students because....I don't want it to be me having stuff that I'm telling you. I want it to be a dialogue. I want the whole class to be a dialogue - a dialogue between students and students, a dialogue between me and students. And that means going both ways. Yes, I'm a teacher. And in some ways, I should be treated as a teacher. But, also, I'm...I'm kind of just the person that's trying to help you reach your goals of language, and that means communicating in a...on a somewhat normal level.

In commenting on his use of humor in the classroom, Paul never actually mentions the word humor. Rather, he focuses on two goals of his teaching philosophy - that of creating a "not-so-top-down approach" and that of creating a 
"dialogue." And he points out that the reaching of these goals requires communication "on a somewhat normal level." Humor, as part of normal conversation, is seen as a sort of equalizing factor in teacher-student interaction. It is, then, seen as one component of classroom interaction that may allow students to realize "aspects of their identities other than simply those of student or learner" (Henry, Korp, Sundqvist, \& Thorsen 2017, p. 19).

\subsection{Making use of Scaffolding Techniques and Providing Opportunities for Peer Scaffolding}

Oxford (1997) sums up the range of scaffolding possibilities by pointing out that "[m]any people can provide the scaffolding that the student needs" (p. 448). When the teacher (normally the de facto expert in the group) provides scaffolding, he/she may control how it is done. The pre-task (Ellis, 2003, Prabhu, 1987), or what Nunan (2004) calls schema building, stands out as a viable option. Peer scaffolding, on the other hand, tends to depend a great deal on the students themselves - as they are the ones who in the end determine the direction that an activity will take (see Lantolf \& Thorne, 2006; Nunan, 1995).

\subsubsection{Making Use of Pre-Task/Schema-Building Techniques}

According to Ellis (2003), the pre-task should motivate learners toward the actual task. One option for this type of preparation is that of "engaging learners in non-task activities designed to prepare them for the task" (Ellis, 2003, p. 245). This option mirrors in many ways the notion of schema building presented by Nunan (2004). According to Nunan, schema-building activities follow a sort of "PPP" (i.e., presentation-practice-production) model: They include setting the context, providing controlled practice, providing authentic listening practice, focusing on linguistic elements, and providing freer practice. In conducting the classes analyzed here, teachers tended to make use of this option.

In tying a lesson based largely on giving descriptions to the unit topic of food, Paul carried out a task in which a student needed to describe a photograph, a meal scene, to a partner who could not see the photograph. Before engaging the students in the task itself, Paul led them through extensive schema-building activities. First, students worked in pairs to describe a photo visible to both members on the large screen in the classroom. Once this segment of the pre-task had concluded, Paul led a debriefing session in which he encouraged more specific descriptions and asked probing questions in order to lead students toward greater specificity, especially in terms of descriptive language and prepositions of location. He then hid the photo and asked students, still working in pairs, to describe the photo again - but with greater specificity. After another short debriefing session, he assigned the actual task, asking one member of each pair to put his/her head down and listen while his/her partner described another photo. Pairs took turns being the "describer" and the "listener," with different photos being shown each time. After each turn, Paul asked leading questions in order to get the "listeners" to report what they had heard as accurately as possible. 
As is evident, Paul led the students through a step-by-step preparation for the photo-describing task. By starting with a description activity in which both students could see the photo, he provided a pre-task with fewer cognitive demands than the actual task would later require. The pre-task no doubt also served the purpose of arousing students' "content schemata," thus providing them with a clear idea of the type of task that they would later be expected to carry out (Ellis, 2003, p. 246). The teacher-led debriefing sessions served to focus learners' attention on language features deemed necessary for successful completion of the actual task.

Shawna's lesson also provided ample evidence of the benefits of schemabuilding activities. In Shawna's class (as in Nick's class), the actual task that the students were to carry out consisted of a small-group project centered around the design and promotion of a themed restaurant for Shantou (i.e., the city in which the learners study). The task itself comprised the second half of the lesson; the first half of the lesson revolved around several schema-building activities. In the first half of the lesson, the teacher showed, on powerpoint slides, authentic photos of various themed restaurants, thus arousing the learners' "content schemata." She also showed a short video clip describing other themed restaurants, thus increasing students' interest in the topic and at the same time providing authentic language input. During this process, the teacher glossed several vocabulary items (e.g., decorations, menu, slogan) that would aid learners in carrying out the actual task.

The following excerpt reveals Shawna's rationale behind such pre-task activities:

Excerpt \#8: Shawna: interview: October 31, 2017

I think [the students] will get the general knowledge of what a themed restaurant is. And, of course, I can see that they get more ideas from section one [of the class] when they are preparing to create the themed restaurant. For example, I put up some key words-decorations, menu, slogan - in section one, right? So, they needed to talk about their own themed restaurant centered around these kinds of topics. And, of course, some students...I think...before creating something new...I think it's better for them to get some visual knowledge.

Shawna's comments indicate that she clearly intended the schema-building activities to provide learners with the background information and the language necessary for successful completion of the task. As the themed restaurants presented through photos and through the video clip ranged from the somewhat revolting (e.g., a toilet restaurant) to the risque (e.g., a nudist restaurant), it would not be unrealistic to suppose that the activities also managed to create an impact and therefore to "arouse and sustain learners' curiosity and attention" (Tomlinson, 2010, p. 95; see also Dörnyei, 2001).

\subsubsection{Providing Opportunities for Peer Scaffolding}

As mentioned above, the students themselves ultimately determine how an activity will unfold. Hence, in considering opportunities for effective peer scaffolding, one might argue that the teacher's job is largely that of creating the right 
conditions (see Ellis, 2003; Mercer \& Howe, 2012; Naughton, 2006; Webb, 2009). In the classes observed, there were very few instances of pair or group work only for the sake of discussion. Instead, pair and group work tended to be focused around a particular, well-specified end goal that encouraged students to negotiate meaning, ask questions, clarify opinions, etc. And the motivation to engage in such behaviors lay in the desire to reach the end goal successfully.

Along with giving students a specific goal for a task (i.e., working in groups to choose the "best" vacation option from among various options), Angela employed other techniques that appeared effectively to promote peer scaffolding. She designated group leaders to keep group members on track. Also, instead of giving each student the handout containing vacation options, she asked group members to share. When asked about the sharing technique, she provided the following answer: Excerpt \#9: Angela: interview: November 8, 2017

There is a big difference [brought about by sharing materials]. If I give each student a copy, they will look at it, and they don't feel the necessity to like...say anything. But if they need to...like...share the copy, they will talk about it. Then, like maybe without knowing it, they will ask like follow-up questions... ask each other more questions.

Angela's comment reveals an awareness of the fact that "structuring materials" may serve as one means of promoting "positive interdependence" within the group (Oxford, 1997, p. 484). Although the actual occurrence of effective peer scaffolding may be somewhat out of the teacher's control, it would seem safe to say that a group-management technique promoting positive interdependence, especially when employed in a clearly goal-oriented task, stands a good chance of leading group members to work together to form a "collective expert."

\subsection{Replacing Textbook Materials in order to Meet Students' Needs/Interests}

In commenting on the importance of "positive affect" in the classroom, Tomlinson (2010) notes that "[l] anguage learners need to be positive about the target language, about their learning environment, about their teachers, about their fellow learners, and about their learning materials" (p. 103; see also Dörnyei, 1994). It follows, then, that textbook materials deemed not to serve the needs of a particular group of learners in a particular setting may need to be replaced (see Maley, 1998/2011; McGrath, 2002; Richards, 2001; Tomlinson, 2010). The teachers observed for the purposes of this study indicated two principal motives for replacing textbook materials: (1) catering to students' needs in terms of reaching task goals and (2) catering to students' needs in terms of providing an appropriate stimulus.

\subsubsection{Catering to Students' Needs in Terms of Reaching Lesson Goals}

Paul, an advocate of combining both content and language goals in lessons and in tasks within lessons, pointed out the way in which a non-textbook video was used to help students reach lesson goals. At one point in the lesson, he wanted his students, in groups, to work together to describe how to make a Chinese dish. Eventually, volunteers from the various groups would need to describe the dish, 
without mentioning the name, and other students would need to guess what dish was being described. In explaining his motive for replacing a textbook video with an Internet-provided video from a cooking program, Paul made the following comment: Excerpt \#10: Paul: interview: October 30, 2017

While this textbook has some good things in it, it might not have things that my students...my specific students... really need help with. So, I might...there might be some things that I may not use, but I'll create my own stuff...that I feel goes along with the goals that I want to share. Like, in the textbook...there was a video of a woman...in a kitchen...cooking. She was kind of demonstrating, and I just didn't like the video. I felt, based on the activity that I wanted my students to do, I kind of felt like my video was a little... better for that. I do think the video certainly helped...to give some ideas of what to say. They can see someone...very short three-minute demonstration...how to make something....

Although Paul does not specify exactly how the replacement video was "better" than the textbook video, one might suppose that it provided more in the way of descriptive language and time-sequence words, two language elements focused upon during the lesson. Also, as the supplementary video was "authentic" in the sense that it was "not produced specifically for learning languages" (Motteram, 1998/2011, p. 306), he may have considered it to be a more effective and realistic model for his students.

\subsubsection{Catering to Students' Needs in Terms of Providing an Appropriate Stimulus}

In various parts of this paper, reference has been made to the task of designing a themed-based restaurant, a task based on locally designed, optional material made available to all teachers of ELC-1. Here it should be noted that the themed-restaurant materials replace the "Unit Task" provided in the standard ELC-1 textbook. The "Unit Task" asks students to make note of their weekly eating habits and then to work with their partners to compare eating habits. Such a task, given elsewhere, might prove fruitful. However, as all students of Shantou University live on campus, as they all eat in the same cafeterias, and as the cafeterias provide limited options, a comparison of eating habits would seem unlikely to produce any significant revelations. Shawna and Nick, therefore, decided to replace the "Unit Task" with the optional task. In commenting on why the themed-restaurant task worked quite well in her class, Shawna made the following observation:

Excerpt \#11: Shawna: interview: October 31, 2017

I think the reason is that they...they really got something in their mind. And the moment they talked to people...they shared their ideas with people....and that is the moment they realized their use of language, right? We are talking about something useful.... We are talking about our opinion exchange. So, I think they could recognize their use of language. We're not just memorizing sentence patterns, reciting new 
words. They really think about...OK...I can communicate with others on some certain topics we've prepared for, and they try to share their personal preference, right?

In answering the question of why the task-based materials seemed to "work" in her class, Shawna makes no reference to the materials themselves. Instead, she focuses on the effect that the materials had on student affect and hence on student involvement - that is, on the stimulus that the learners received from the materials. In doing so, she emphasizes three of the principles of materials development mentioned by Tomlinson (2010):

- Provide the learners with opportunities to use the target language to achieve communicative purposes.

- Achieve impact in the sense that they arouse and sustain the learners' curiosity and attention.

- Stimulate intellectual, aesthetic, and emotional involvement (p. 95).

From Shawna's point of view (and, incidentally, from the observer's point of view), the themed-restaurant materials clearly seemed to meet these three criteria. The novelty of the materials caught students' attention, and the creativity required in designing the restaurant sparked the "intellectual, aesthetic, and emotional involvement" that motivated the learners to "use the target language to achieve communicative purposes."

\section{CONCLUSION}

This study set out to examine the ways in which teachers' classroommanagement techniques may influence student participation (or lack of participation). Through a careful review of data collected through class observations and filmings, interviews with the teachers of the observed classes, and field notes, the study lends support to one of the principal arguments made by Cheng (2000): Chinese students "are not culturally predisposed to be reticent and passive in language learning" (p. 438). It indicates that Chinese language learners are indeed quite happy to participate in a creative way as long as they have sufficient motivation to do so.

First, students willingly participate in an appropriate classroom setting-one which allows for an expectation of success, for opportunities to break out of the monotony of the teacher-fronted classroom, and for a healthy dose of humor. Second, effective scaffolding in the form of pre-task and during-task group or pair work seems to lead to an increase in participation. Specifically, time allotted for the co-construction of meaning prior to task engagement and during task engagement appears to increase student confidence and to increase the likelihood of active involvement. Finally, while prescribed textbooks may serve to give teachers a course guide (see Harwood, 2010), they cannot be guaranteed to meet the specific goals of specific students, nor can they be guaranteed to provide specific students with an appropriate stimulus. Hence, the meeting of students' needs would seem to require careful replacement of the textbook with more situation-appropriate materials. 
The study also provides empirical evidence to support to the notion of a "pedagogy of particularity" (Kumaravadivelu, 2001), a notion which stipulates that "language pedagogy, to be relevant, must be sensitive to a particular group of teachers teaching a particular group of learners pursuing a particular set of goals within a particular institutional context embedded in a particular sociocultural mileau" (p. 538). During the interviews discussed here, Paul made this point patently clear in commenting on his practice of replacing textbook materials in order better to aid his particular students in reaching the particular goals that he wanted to share. Likewise, Shawna indicated that her replacement of the standard textbook task with a locally designed task led to a high level of motivation that resulted in enthusiastic interaction among students. In both cases, as in other cases discussed here, there were clear indications that the employed techniques produced the intended goal of preparing learners both affectively and cognitively to be active participants in their English lessons. In short, the findings here provide evidence of classroommanagement techniques promoting student involvement; a sensitivity to institutional context suggests that these findings also need to be tested in other Chinese settings.

\section{REFERENCES}

Antón, M., (1999). The discourse of a learner-centered classroom: Sociocultural perspectives on teacher-learner interaction in the second-language classroom. The Modern Language Journal, 83(3), 303-318.

Bejarano, Y. (1987). A cooperative small-group methodology in the language classroom. TESOL Quarterly, 21(3), 483-504.

Block, D. (1996). A window on the classroom: Classroom events viewed from different angles. In K. M. Bailey \& D. Nunan (Eds.), Voices from the language classroom (pp. 168-194). Cambridge, UK: Cambridge University Press.

Block, D. (2003). The social turn in language acquisition. Edinburgh, UK: Edinburgh University Press Ltd.

Brindley, G. (1984). Needs Analysis and Objective Setting in Adult Migrant Education. Sydney, Australia: Adult Migrant Education Service.

Chang, L. Y-H. (2010). Group processes and EFL learners' motivation: A study of group dynamics in EFL classrooms. TESOL Quarterly, 44(1), 129-154.

Cheng, X. (2000). Asian students' reticence revisited. System, 28, 435-446.

Chinese Ministry of Education (2007). College English curriculum requirements. Beijing: Tsinghua University Press.

Clément, R., Dörnyei, Z., \& Noels, K. (1994). Motivation, self-confidence, and group cohesion in the foreign language classroom. Language Learning, 44(3), 417-448.

Crabbe, D. (2003). The quality of language learning opportunities. TESOL Quarterly, 37(1), 9-34.

Crabbe, D. (2007). Learning opportunities: Adding value to tasks. ELT Journal, 61(2), 117-125.

Cortazzi, M., \& Jin, L. (1996). Cultures of learning: Language classrooms in China. In $\mathrm{H}$. 
Coleman (Ed.), Society and the language classroom (pp. 169-206). Cambridge: Cambridge University Press.

Donato, R. (2004). Aspects of collaboration in pedagogical discourse. Annual Review of Applied Linguistics, 24, 284-302.

Dörnyei, Z. (1994). Motivation and motivating in the foreign language classroom. The Modern Language Journal, 78(3), 273-284.

Dörnyei, Z. (2001). Motivational strategies in the language classroom. Cambridge, UK: Cambridge University Press.

Dörnyei, Z. (2007). Research methods in applied linguistics: Qualitative, quantitative and mixed methodologies. Oxford, UK: Oxford University Press.

Dörnyei, Z., \& Malderez, A. (1997). Group dynamics and foreign language teaching. System, 25(1), 65-81.

Dörnyei, Z., \& Murphey, T. (2003). Group dynamics in the language classroom. Cambridge, UK: Cambridge University Press.

Effiong, O. (2016). Getting them speaking: Classroom social factors and foreign language anxiety. TESOL Journal, 7(1), 131-161.

Ellis, R. (2003). Task-based language learning and teaching. Oxford, UK: Oxford University Press.

Flowerdew, J., Miller, L. (1995). On the notion of culture in L2 lectures. TESOL Quarterly 29(2), 345-373.

Freeman, D. (1996). Redefining the relationship between research and what teachers know. In K. M. Bailey \& D. Nunan (Eds.), Voices from the language classroom (pp. 88-115). Cambridge, UK: Cambridge University Press.

Freeman, D. (2002). The hidden side of the work: Teacher knowledge and learning to teach. A perspective from North American educational research on teacher education in English language teaching. Language Teaching, 35(1), 1-13).

Friedman, D. A. (2012). In A. Mackey \& S. M. Gass (Eds.), Research methods in second language acquisition: A practical guide (pp. 74-94). West Sussex, UK: Wiley-Blackwell.

Harwood, N. (2010). Issues in materials development and design. In N. Harwood (Ed.), English language teaching materials: Theory and practice (pp. 2-34). Cambridge, UK: Cambridge University Press.

Hedge, T. (2000). Teaching and learning in the language classroom. Oxford: Oxford University Press.

Henry, A., Korp, H., Sundqvist, P., \& Thorsen, C. (2017). Motivational strategies and the reframing of English: Activity design and challenges for teachers in contexts of extensive extramural encounters. TESOL Quarterly. doi:10.1002/tesq.394.

Hu, G. (2005). Contextual influences on instructional practices: A Chinese case for an ecological approach to ELT. TESOL Quarterly, 39(4), 635-660.

Jin, J., Liu, H., \& Zhang, Y. (2015). A research on students' needs for follow-up curriculum of college English. Journal of Education and Training Studies, 3(1), 116-128.

Kumaravadivelu, B. (1994). The postmethod condition. TESOL Quarterly, 28(1), 27-48. 
Kumaravadivelu, B. (2001). Toward a postmethod pedagogy. TESOL Quarterly, $35(4), 537-560$.

Kumaravadivelu, B. (2003). Problematizing cultural stereotypes in TESOL. TESOL Quarterly, 37(4), 709-719.

Lantolf, J. P., \& Thorne, S. L. (2006). Sociocultural theory and the genesis of second language development. Oxford, UK: Oxford University Press.

Li, M., \& Baldauf, R. (2011). Beyond the curriculum: A Chinese example of issues constraining effective English language teaching. TESOL Quarterly, 45(4), 793-803.

Lin, T.-B., \& Wu, C.-W. (2012). Teachers' perceptions of task-based language teaching in English classrooms in Taiwanese junior high schools. TESOL Journal, 3(4), 586-609.

Liu, M., \& Jackson, J. (2008). An exploration of Chinese learners' unwillingness to communicate and foreign language anxiety. The Modern Language Journal, 92(1), 71-86.

Liu, N. F., \& Littlewood, W. (1997). Why do many students appear reluctant to participate in classroom learning discourse? System 25(3), 371-384.

Maley, A. (2011). Squaring the circle-Reconciling materials as constraint with materials as empowerment. In B. Tomlinson (Ed.), Materials development in language teaching ( ${ }^{\text {nd }}$ ed.). (pp. 379-402). Cambridge, UK: Cambridge University Press.

McGrath, I. (2002). Materials evaluation and design for language teaching. Edinburgh, UK: Edinburgh University Press.

Mercer, N., \& Howe, C. (2012). Explaining the dialogic processes of teaching and learning: The value and potential of sociocultural theory. Learning, Culture and Social Interaction, 1, 12-21.

Motteram, G. (2011). Developing language-learning materials with technology. In B. Tomlinson (Ed.), Materials development in language teaching ( $2^{\text {nd }}$ ed.). (pp. 303-327). Cambridge, UK: Cambridge University Press.

Naughton, D. (2006). Cooperative strategy training and oral interaction: Enhancing small group communication in the language classroom. The Modern Language Journal, 90(2), 169-184.

Nunan, D. (1995). Closing the gap between learning and instruction. TESOL Quarterly, 29(1), 133-158.

Nunan, D. (1996). Hidden voices: Insiders' perspectives on classroom interaction. In K. M. Bailey \& D. Nunan (Eds.), Voices from the language classroom (pp. 4156). Cambridge, UK: Cambridge University Press.

Nunan, D. (2004). Task-based language teaching. Cambridge, UK: Cambridge University Press.

Oxford, R. L. (1997). Cooperative learning, collaborative learning, and interaction: Three communicative strands in the language classroom. The Modern Language Journal, 81(4), 443-456.

Pomerantz, A., \& Bell, N. D. (2011). Humor as safe house in the foreign language classroom. The Modern Language Journal, 95, 148-161.

Prabhu, N. S. (1987). Second language pedagogy. Oxford: Oxford University Press. 
Swanson, P. B. (2013). Spanish teachers' sense of humor and student performance on the National Spanish Exams. Foreign Language Annals, 46(2), 146-156.

Tomlinson, B. (2010). Principles of effective materials development. In N. Harwood (Ed.), English language teaching materials: Theory and practice (pp. 93-125). Cambridge, UK: Cambridge University Press.

Tsui, A. B. M. (1996). Reticence and anxiety in second language acquisition. In K. M. Bailey \& D. Nunan (Eds.), Voices from the language classroom (pp. 144167). Cambridge, UK: Cambridge University Press.

Webb, N. B. (2009). The teacher's role in promoting collaborative dialogue in the classroom. British Journal of Educational Psychology, 79, 1-28.

Wells, G. (1999). Dialogic inquiry: Toward a sociocultural practice and theory of education. Cambridge, UK: Cambridge University Press.

Xie, J. (2014). Challenges and opportunities for the pluricentric approach in ESL/EFL teaching. English Today, 30(2), 43-50.

Xie, X. (2010). Why are students quiet? Looking at the Chinese context and beyond. ELT Journal, 64(1), 10-20.

Zhu, H. (2003). Globalization and new ELT challenges in China. English Today, 19(4), 36-41. 